\title{
Are Weighted Monetary Aggregates Better Than Simple-Sum M1?
}

\author{
Dallas S. Batten and Daniel L. Thornton
}

T

HE past 10 years have been marked by financial innovation and deregulation, much of which has blurred the distinction between transaction and savings deposits. Traditional non-interest-bearing transaction deposits now pay explicit interest like savings deposits, while a number of savings-type deposits with limited transaction characteristics have been developed.

A number of analysts believe that these financial developments have altered significantly the relationship between M1 growth and the growth of GNP. rendering the narrow monetary aggregate less useful as an intermediate target for monetary policy.' Others have objected on broader grounds, arguing that these innovations illuminate the problem of simply adding up various financial assets currency, demand deposits, NOW accounts, etc.l to obtain a "simple-sum" monetary aggregate. They argue that various assets have different degrees of "moneyness" - that is, the

Dallas $S$. Batten is a research officer and Daniel $L$. Thornton is a senior economist at the Federal Reserve Bank of St. Louis. Paul G. Christopher and Rosemarie V. Mueller provided research assistance.

The Federal Open Market Committee was so concerned by these developments that it altered the relative weights given to $\mathrm{M} 1$ and the broader monetary aggregates several times during the 1981-82 period in making its policy recommendations and suspended the use of M1 as an intermediate policy target in fall 1982. Furthermore, some analysts have been so concerned that $M 1$ is no longer a useful target of monetary policy that they have suggested a retum to the Keynesian system of interest rate fargets or a reliance on a broader simple-sum monetary aggregate, like $\mathrm{M} 2, \mathrm{M} 3$ or some measure of credit, as an internediate target. Still others have suggested that the Fed target directly on nominal GNP (though the procedures for pursuing this target are seldom discussed in detail). See Thornton (1982, 1983). Simple-sum M1 was re-introduced as an intermediate policy target in 1984; see Hater (1985).

These other suggestions have been investigated elsewhere. The use of interest rates as an intermediate policy target is predicated on the existence of a liquidity eftect, which has been shown to be shortlived and weak. See Brown and Santoni (1983) and Melvin (1983). For empirical evidence on $\mathrm{M} 1$ and $M 2$, see Batten and Thornton (1983) and on the broader debt measure, see Hafer (1984).

monetary services that each asset provides - so that the dollar amount of each asset should be weighted by its degree of moneyness in obtaining a suitable monetary aggregate. Such an aggregate presumably should have a closer and more predictable relationship with economic activity and may be affected less by financial innovations. The most novel and innovative suggestions have come from individuals who have constructed weighted monetary aggregates based on alternative theoretical considerations. Two recent and popular innovations along these lines come from $W \mathrm{il}-$ liam Barnett (1980) and Paul Spindt (1985):

A central issue now is whether weighted monetary aggregates are better intermediate policy targets than simple-sum aggregates like M1. A necessary condition for using a monetary aggregate as an intermediate policy target is that there be a close and predictable relationship between the monetary aggregate target and the objectives of economic policy. Thus, if an aggregate can be found that has a closer and more predictable link to economic activity, it could be useful in conducting countercyclical stabilization policy."

The purpose of this article is threefold. First, we review briefly the important issues associated with constructing weighted and simple-sum monetary aggregates and discuss the alternatives suggested by Barnett and Spindt. Second, we compare and contrast these weighted monetary aggregates with simple-sum M1. Finaliy, we investigate whether there is a more stable and predictable relationship between the alter-

2Earlier work along these lines includes Chetty (1967) and Hamburger (1966).

3The strength of the relationship between the ultimate goals of policy and the intermediate policy target is only one of the criteria for evaluating a monetary target.

${ }^{4}$ This should not be interpreted to imply that monetary policy can be used successfully for short-run economic stabilization. This is merely a necessary condition; it is not sufficient. 
natives proposed by Barnett and Spindt and GNP, than between simple-sum M1 and GNP. We investigate this by examining the behavior of the income velocity of each of these aggregates.

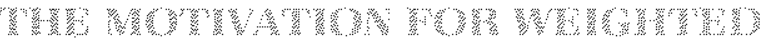

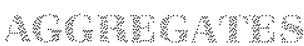

Monetary theory has emphasized two different, but not mutually exclusive, functions of money: a medium of exchange and a store of wealth. The medium-ofexchange function was emphasized in the work of Fisher (1911), while the store-of-wealth motive was emphasized by Pigou (1917), Marshall (1923) and Keynes (1936). It has been recognized for some time that different financial assets perform these functions to different degrees. For example, currency and demand deposits are both generally acceptable as media of exchange, but are not perfect substitutes for this purpose in all transactions. Furthermore, these assets bear no explicit interest and, as a consequence, are poor stores of wealth relative to interest-bearing savm ings and time deposits of equal risk.

Because assets such as time and savings deposits cannot be used directly in exchange, it was common to define money to include only medium-of-exchange assets. It was not until Friedman (1956), Friedman and Meiselman (1963) and Friedman and Schwartz (1970) emphasized money's role as a "temporary abode of purchasing power" (i.e., a temporal bridge between the sale of one item and the purchase of anotherl, that it became common to consider broader monetary aggregates that included non-medium-of-exchange assets."

Once the medium-of-exchange line of demarcation between money and non-money assets was breached, however, it became difficult to isolate any other characteristics that differentiate money from non-money

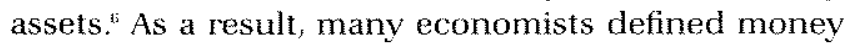
as that group of assets that satisfied some empirical

\footnotetext{
${ }^{5}$ According to Laidler ( 1969 ), the debate about whether non-mediumof-exchange assets are money dates back, at least, to the Napoleonic wars.

${ }^{6}$ Some characteristics that have been used include liquidity, substitutability between non-medium-of-exchange and pure medium-ofexchange assets, and the strength and stability of the relationship between a composite of various financial assets and nominal in come. Additionally, Pesek and Saving (1967) have argued that, since money has its primary effect on the economy through a wealth effect, an asset's moneyness should be determined by the exterit to which it is parl of society's net wealth. See Laidier (1969) for a discussion of this point.
}

criteria.: Perhaps the most frequently used criterion was the closeness of the relationship between a particular monetary aggregate and GNP."

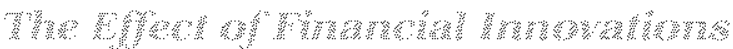

The difficulty in distinguishing between money and non-money assets has been exacerbated by financial innovation and deregulation. Several savings-type assets with limited transaction characteristics have been developed le.g., money market mutual funds (MMMFs), money market deposit accounts (MMDAs) and automatic transfer services (ATS) and mediumof-exchange assets now pay explicit interest leg., NOWs and Super NOWs). Additionally, there have been a number of other innovations that have increased the substitutability between medium-ofexchange and non-medium-of-exchange assets, such as overnight repurchase agreements (REPOs) and conlinuous compounding of interest on savings-type deposits. Hence, the distinction between transactionand savings-type assets has been blurred even more.

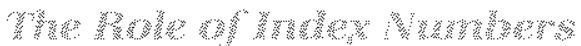

If different assets have different degrees of moneyness, we may wish to aggregate (add) them with respect to this homogeneous characteristic. This point can be made more clearly with a physical example. $A$ ton of coal, a kilowatt of electricity and a barrel of oil are not homogeneous in terms of their volumes or weights and, hence, cannot be aggregated in terms of these measures. If, however, we are concerned with their energy equivalences, measured say by BTUs, they can be thought of broadly as homogeneous and can be aggregated in terms of their BTU equivalence. The

\footnotetext{
${ }^{7}$ Although not als of the studies have employed the same empirical criteria, many have focused on the relationship between the proposed monetary aggregate(s) and economic activity. Furthermore, not all agree that money can be defined empirically, e.g. Mason (1976).

${ }^{8}$ Frequently, the assets considered had to satisfy an auxiliary condition, for example, they must be "gross substifutes." See Friedman and Sctiwatz (1970) or Friedman and Meiselman (1963).

The impact of these innovations on the substitutability between medium-of-exchange and non-medium-of-exchange assets can be made clear via an example. At one sime, it was common for depository institutions to compound interest quarterly on savings and time deposits, so that interest was paid only on balances on deposit on the day of compounding. Such practices severely limited the advan. tage of these accounts over demand deposits as temporary abodes of purchasing power, since the interest income gain from temporar ify switching from demand deposits to savings deposits could be lost if the transaction had to be made prior to the quarterly compounding date. Other changes that permitted an easier transfer between medium-of-exchange and non-medium-of-exchange assets would have a similar effect.
} 
same is true for aggregating financial assets, but, since they are expressed in dollars, it may seem more natural simply to add dollar amounts of assets that have a high degree of moneyness, however defned. This is the rationale for the construction of simple-sum monetary aggregates.

Unfortunately, adding dollar amounts of assets is not the same as aggregating them by a homogeneous measure of their moneyness. As the dollar amounts of various components change through time, they may represent different levels or degrees of moneyness. Conversely, the same dollar value of the aggresate composed of different dollar values of its various com ponents may not represent the same level of monetary services. Consequently, the dollar isimple-sum aggregate may misrepresent the amount of such services provided.

Index numbers can be used to aggregate assets by a homogeneous characteristic. Conceptualy, they enable the construction of an aggregate based on this characteristic so that changes in the index reflect only changes in some quantitative measure of this characteristic. It is not surprising, therefore, that both Barnett and spindt use index aggnegation to construet their alternative weighted monetary aggregates. The assets included in simple-sum M1, Bamett's broadest monetary aggregate (MSI4) and Spindt's aggregate (MO) appear in the insert on this page.

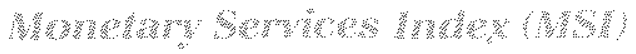

Bamett has developed a number of monetary aggregates based on the idea that the essential function of money is to bridge the temporal gap between the sale of one item and the purchase of another. Assets that serve this purpose must be easily and quickly convertible into and out of nedium of exchange assets. Following a suggestion of Friedman and Schwartz [1970) - see Bamett and Spind $(1982)$ - Bamett extends the approach of estimating the substitutability between non-medium-of-exchange assets and a pure mediumof-exchange asset employed by Chetw 11969), Hamburger 1966 and others. Specifically, he applies index number theory to constmet indexes of financial assets that reflect the total utility, relative to some base pe

\footnotetext{
"Other monetary service indexes (MSI) include the assets in simple. sum M1, M2 and M3. We ignore these here because MS1 is the only MSI that has an intuitively appealing rationale, given the asset motive on which it is based. In particular, it attempts to extract the "moneyress" from a broad range of financtal assets. In contrast, the narrower MSl are constrained by the assets arbitarty included in each.
}

\begin{tabular}{|c|c|c|c|}
\hline \multicolumn{4}{|c|}{$\begin{array}{l}\text { Medium-of-Exchange Assets and the } \\
\text { Defintion of Monetary Aggregates }\end{array}$} \\
\hline & $\begin{array}{l}\text { Simple } \\
\text { sum }\end{array}$ & Mo & NS14 \\
\hline \multicolumn{4}{|l|}{ Medium-of-Exchange Assets } \\
\hline Currency a & $X$ & $x$ & $x$ \\
\hline Travelers checks & $x$ & $x$ & $x$ \\
\hline Demand deposits & $x$ & $x$ & $x$ \\
\hline Other checkable deposits: & $x$ & $\mathrm{x}$ & $x$ \\
\hline $\begin{array}{l}\text { Credil unton share draft } \\
\text { accounts }\end{array}$ & $x$ & $X$ & $x$ \\
\hline MMOAs $\quad$ - & & $x$ & $x$ \\
\hline MAMFs $\quad$ Q & & $x$ & $x$ \\
\hline $\begin{array}{l}\text { Savings deposts sutfect } \\
\text { to telephone transfer }\end{array}$ & & $x$ & $x$ \\
\hline \multicolumn{4}{|c|}{ Non-Mediumot-Exchange Assets } \\
\hline $\begin{array}{l}\text { Savings deposits not } \\
\text { subject to telephone } \\
\text { uransfer }\end{array}$ & & & $x$ \\
\hline Small ine deposits & & & $\mathrm{x}$ \\
\hline REPOs & & & $x$ \\
\hline Eurodolar deposits & & & $\mathrm{x}$ \\
\hline Large lime deposits & & & $x$ \\
\hline US savings bonds & & & $x$ \\
\hline $\begin{array}{l}\text { Shontem Treasury } \\
\text { securites }\end{array}$ & & & $x$ \\
\hline Commercal paper & & & $\mathrm{x}$ \\
\hline Bankers acceptances & & & $\mathrm{x}$ \\
\hline
\end{tabular}

niod, atributable to the monetary services obtained from these assets."

This approach can be easily understood by thinking of assets that provide monetary services as being on a continuum with pure medium-of-exchange assets fcurencyl at one end and "pure" store-of-wealth assets at the other. The pure medium-of-exchange assets earn no interest and are useful only as a medium-

\footnotetext{
"The construction of these aggregates need not be based solely on a utility maximization approach. If it is based on other objective functions, however, its interpretation is altered.

Originaily, Bamett called these aggregates "Divisia monetary aggregates" because a Divisia index was used to construct them. The Federal Reserve Board, under whose auspices these aggregates were originally constructed and are still maintained, has recently undertaken a substantial revision to correct inconsistencies and errors in the original computer programs and data, and to incorporate new data not readily avallable at the lime these aggregates were intially constructed; see Farr and Johnson (1985). The Divisia index is no longer used to construct these aggregates. Consequentsy, they are no longer referred to as Divisia monetary aggregates but are now called "monetary services indexes" (MSI). Since the data reported here reflect these recent changes, this new ternirology is adopted here as well.
} 
of exchange: The pure store-of-wealth assets earn $c$ market interest rate but are not useful as a temporary abode of purchasing power, although they may be used to transfer purchasing power over longer periods of time. Consequently, the latter group of assets provides no monetary services by this criterion. The assets that fall between these extremes yield monetary services greater than zero but less than those of the pure medium-of-exchange assets.

The monetary -service flow from each asset is based on its "user cost" as measured by the difference between the rate of interest on a pure store-of-wealth asset and the own rate of retum on each asset. Curm rency, which has an own rate of zero, has the highest user (opportunity) cost. Medium-of-exchange assets like demand deposits (which bear no explicit interest, but bear some implicit interest, e.g., gifts or no service charges ' have a smaller user cost and, hence, receive a smaller weight. Non-medium-of-exchange assets that yield explicit returns closer to those of the pure storeof-wealth assets receive still smaller weights.

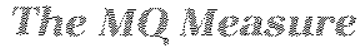

Spindt's weighted monetary aggregate, $M O$, is an index of transaction assets whose weights are based on each asset's turnover, along lines originally suggested by Fisher (1922). This measure is based on a pure transaction approach to money and, thus, marks a clear departure from the MSI of Barnett. Furthermore, Spindt's measure weights each of its components by a measure of turnover in purchasing final output (GNP); assets with relatively high tumover rates receive relatively larger weights.

Despite the fact that the turnover rates are used in the calculation of $\mathrm{MQ}$, the money stock measure moves only when there is a change in monetary services between periods, so that its velocity changes only when there is a change in the turnover rates. In

\footnotetext{
12Technically, currency, tike all financial assets, also acts as a store of wealth; however, the argument is that there exists an asset (fully insured savings deposits) that pertom this function better with equal risk. Consequently, no maximizing individual would willingly hold currency purely as a store of wealth given such an alternative.

13t is clear from this discussion that two distinct, but related, issues are involved here. The first centers around whether the asset or transactions measure (approach) is preterable. The second is a question of the appropriate weighting scheme. These issues are related in the sense that if the asset approach is preferred, then, by implication, the MSI weighting scheme is preferred as well, since not all of these assets can be used directly in transactions. If the transactions approach is preferred, however, the question of the weighting scheme remains open. The best weighting scheme may still involve the difference between the own rate and the rate on the most liquid non-medium-of-exchange asset.
}

contrast, the velocity of the MSI and simple-sum M1 can change even if there is no change in their turnover rates. Hence, we should expect to see a more stable relationship between MQ and GNP.'+

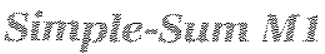

By weighting each component equally, simple-sum aggregates implicitly assume that each component is a perfect substitute for the others in providing monetary services. Furthermore, the narrow aggregate, simple-sum $M 1$, excludes both non-medium-ofexchange assets and some assets with limited transaction characteristics like MMMFs and MMDAs. The broader simple-sum aggregates, like M2, M3 and the Fed's broadest measure, total liquidity $(\mathrm{L})$, include larger amounts of non-medium-of-exchange assets. Consequently, these broader simple-sum aggregates may misrepresent significantly the monetary services provided by including non-medium-of-exchange assets, which provide relatively low levels of monetary services, on an equal footing with medium-ofexchange assets, which provide relatively high levels of monetary services.

A financial innovation that results in a shift from assets not in simple-sum M1 to assets in simple-sum M1 would cause the same change in measured money, regardless of the source of the shift. In contrast, similar innovations would cause different changes in the MSI or MQ. The extent of the impact depends on the difference between the asset's own rate of return and that of the pure store-of-wealth asset (for the MSI) and on the asset's relative turnover rate in the purchase of goods and services (for MQ).

As a result, these new aggregates may be affected less by innovations. For example, to the extent that the nationwide introduction of NOW accounts on January 1, 1981, drew deposits out of savings accounts (i.e., idle balances/ into NOW accounts, the growth of simplesum M1 would be inflated. In contrast, because NOW accounts bear an interest rate closer to the pure storeof-wealth rate, they receive a smaller weight in the MSI. Consequently, if this regulatory change resulted in a significant shift out of savings-type assets into NOW accounts, the MSI might be affected less by this regulatory change.

To the extent that NOW accounts are used predominantly as a store of wealth rather than a medium of exchange, MQ would be affected to a lesser degree

\footnotetext{
${ }^{14}$ For a discussion of this point, see Spindt (1985). At a more technical level, Spindt (1983) has shown that it is only possible to interpret these aggregates sensibly by using an intertemporal measure.
} 
Chart 1

Growth Rates of Monetary Aggregates

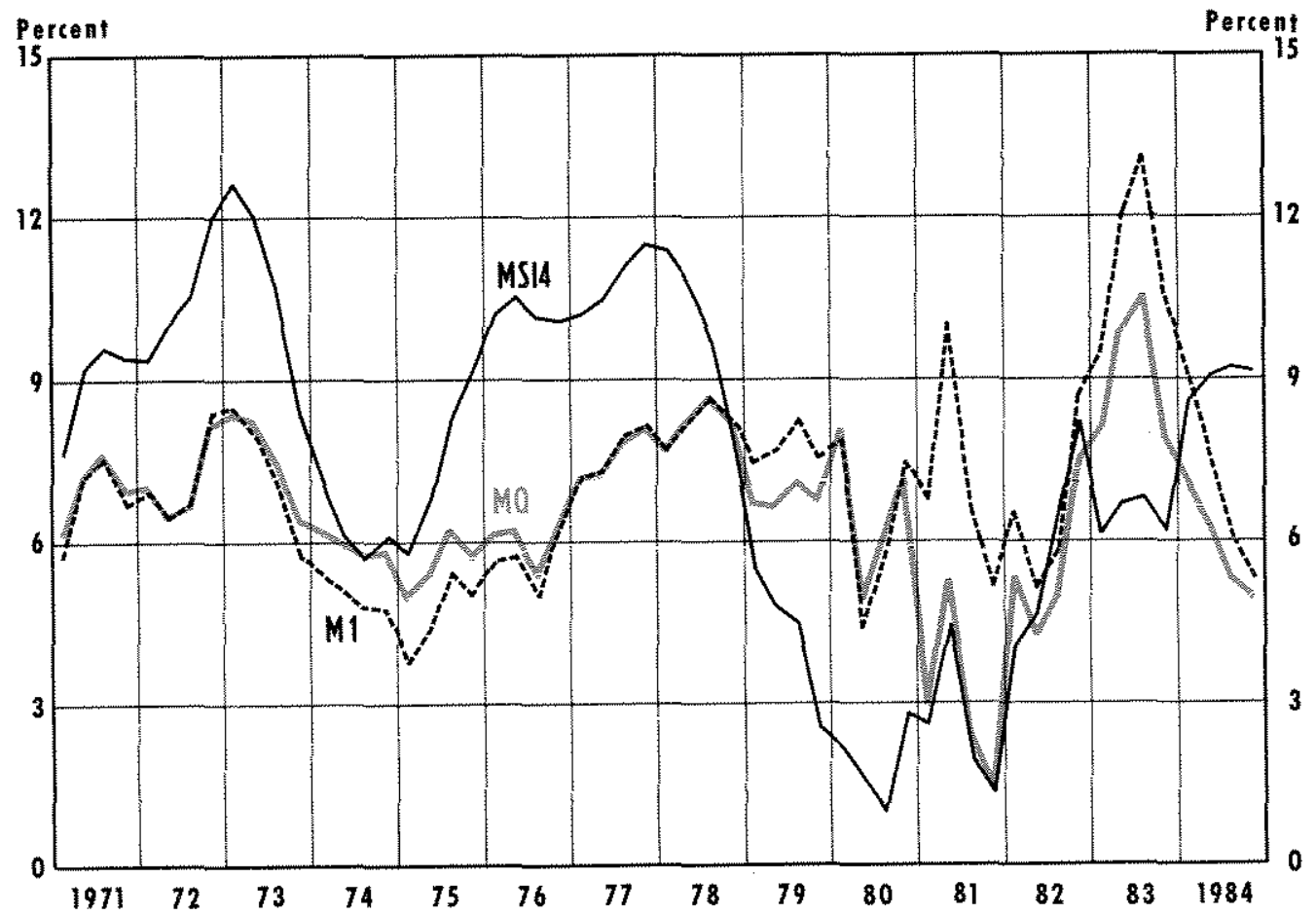

than simple-sum M1 by NOW account growth because Now accounts initially had a lower turnover rate in transactions than did currency and demand deposits. Also, MQ and broader MSI contain savings-type assets not included in simple-sum M1 leg, money market mutual funds). Consequently, their growth rates would be affected less if the growth in NOW accounts resulted from a shift out of such deposits. If, however, most of the growth in NoWs came from demand deposits, then simplemsum M1 would be relatively unaffected and the glowth of both MQ and the MSI would decrease since demand deposits had larger weights than NOWs in MQ and the MSI.

The advantage these aggregates propose to offer, however, is not without costs. The calculation of the weights in the MSI and MQ requires more information than that required to construct simple-sum M1. Con* sequently, the construction of these alternative aggregates may introduce larger measurement and specification errors than those of omission and inappropriate weighting associated with simple-sum $M 1$ isee the insert on the next pagel. ${ }^{1.5}$

"We say "might be" here for several reasons. What is the appropriate

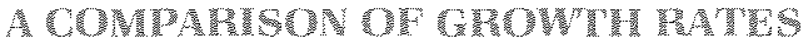

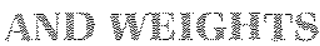

As an initial step in the examination of altenatives to simple-sum M1, a comparison of the year-over'year growth rates of simple-sum M1 hereafter denoted as ML, MQ and the broadest monetary service index (MSI4) is presented in chart 1 . Several interesting points emerge.

First, the growth rate of MSI4 has not conformed to that of the other two monetary aggregates anytime during the $1 / 1971-$ IV/1984 period. Second, up to 1981 . the growth rates of $\mathrm{M} 1$ and $\mathrm{MQ}$ are similar and move together. The mean growth rates for $\mathrm{M} 1$ and $\mathrm{MQ}$ over the $I / 197 /-I V / 1980$ period ate 6.6 and 6.8 percent, yespectively; the standand deviations for the same aggregates are 1.36 and 1.00 percent, respectively. On the other hand, MSI4 growth during this period is significantly higher and more variable; its average growth was 8.08 percent with a standard deviation of 3.26

weighting scheme is an open question. Furthermore, if we could decide on the most appropriate scheme from a theoretical point of view, the magnitude of the weights would still be an empirical issue. 


\section{Information and Estimation Requirements of the MSI and MO Aggregates}

The construction of the monetary service indexes and MO require more information than is entailed in the construction of a simple-sum aggregate with dentical components. In each case, data on the quantities of each component are necessary; however, both the MSI and MO require additional information and hence, are open to sources of error not contained in the simple-sum aggregates.

The MSt require information that is often incomplete or unavailable consequently, certain explicit (or in some cases, implicit) asstimptions are made that may render them less useful as intermediate policy targets. First, they use information on the own rate of interest on each component, In many cases, actual data are unavailable so they must be assumed, estimated or set equal to some ceiling rate. For example, the rates on passbook savings deposits at mutual savings banks and savings and loans are assumed to be at their ceiling rates while the rate on demand deposits held by businesses are proxied by the rate on directly placed finance company commercial papes adjusted for reserve requirements.

The own rate of retum on all currency and demand deposits held by households is assumed to be zero At first, this may seem inappropriate because the own rate of retum to holding currency is the negative of the expected rate of inflation. This assumption is appropriate, however, as long as the interest rate on the pure store-of-wealth asset Moody's series of seasoned Baa bonds also reflects expectations of inflation, Nevertheless, changes in inflationary expectations may distort the measure of monetary services associated with other components because many of these rates are set at ceiling levels that will not respond rapidly to changing expectations of inflation. Hence, the estimate of the user cost may erroneously change with changes in expectations of inflation. This assumption, however, is less appropriate in the case of demand deposits because such deposits may yield some explicit retum.

Furthermore, the theoretical model on which these aggregates are based requires that all vields be for an equivalent holding period As a result all assets are converted to a one-month holding period yield by a Treasury secumities yield curve adjustment Moreover, the reference rate that deternines the user cost is the maximum of the Baa corporate bond rate and he rates on the assets contamed in the aggregate. Therefore, the user costs are sensitive to changes in the vield curve in addition to these, a number of other estimations. and assumptions are made see farr and Johnson (1985).

Likewise, Spindt's MO measure is based on a number of assumptions necessitated by measurement problems, For example, no tumover statistics are available for either currency or travelers checks and the turnover statistics for the other components are gross turnover, not final product GNPI turnover, as is necessary to be consistent with the underlying theory. As a result, a number of assumptions and estimates are made to generate the final product tumover rates used in the construction of MQ (see Spindt 1983).

The extent to which these aggregates are affected by the various estimates and implicit assumptions is, of course unknown it could be that there exists a "Taw of large numbers' so that on average, these: measurement errors cancel each other No such. law, however, need exist Consequently, the potential advantages that these aggregates might offer must be determined by statistical comparisons like those presented here of course, if such comparisons show ittle or no advantage of these aggregates over simple-sum aggregates, it suggests that we need to rethink the theory on. which they are based or the way in which these aggregates are estimated. 
Table 1

Weights For Calculating Growth Rates of the Aggregates ( $\times 100$ )

\begin{tabular}{|c|c|c|c|c|c|c|c|c|c|c|c|c|}
\hline \multirow[b]{2}{*}{ Year } & \multicolumn{3}{|c|}{ Mi } & \multicolumn{4}{|c|}{ no } & \multicolumn{5}{|c|}{ MSI4 } \\
\hline & cte & BD & OcDI & ctc & Do & Ocol & $\mathrm{OCp}_{2}$ & сто & Do & ocol & ocor & OTHER \\
\hline 1970 & 230 & 76.9 & 0.1 & 45.3 & 547 & 0.0 & 0.0 & 127 & 234 & 00 & 00 & 639 \\
\hline 1971 & 23.2 & 768 & 0.1 & 448 & 552 & 00 & 00 & 117 & 270 & 00 & 0.0 & 61.3 \\
\hline 1972 & 261 & 70.8 & 01 & 43.4 & 56.6 & 00 & 00 & $\sqrt{177}$ & 274 & 0.0 & 0.0 & 640 \\
\hline 1973 & 234 & 76.5 & 0,1 & 406 & 59.5 & 00 & 0.0 & 13.4 & 243 & 00 & 0.0 & 622 \\
\hline 1974 & 245 & 754 & 01 & 375 & 62.5 & 0.1 & 0.0 & 13.6 & 231 & 00 & 00 & 63.3 \\
\hline 1976 & 257 & 741 & 02 & 368 & 630 & 01 & 011 & 10.6 & 21.2 & 01 & 02 & 68. \\
\hline 1976 & 267 & 728 & 0.6 & 34.5 & 651 & 0.3 & 0.1 & 10.6 & 21,2 & 04 & 0.2 & 68.0 \\
\hline 1977 & 27.1 & 719 & 11 & 32.8 & 66.6 & 05 & 0.1 & 119 & 21.5 & 0.2 & 01 & 662 \\
\hline 1978 & 27.5 & 710 & 15 & 30.9 & 683 & 0.5 & 02 & 137 & 207 & $0_{4}$ & 02 & 650 \\
\hline 1979 & 28.1 & 681 & 38 & 286 & 69.5 & 1,1 & 08 & 15.9 & 20.4 & 13 & 0.4 & 620 \\
\hline 1980 & 28.9 & 657 . & 5.4 & 270 & 689 & 21 & 20 & 137 & 171 & 17 & 1.5 & 654 \\
\hline 1981 & 290 & 55.8 & 152 & 24.3 & 634 & 94 & 33 & 15.6 & 155 & 58 & 16 & 6155 \\
\hline 1982 & 29.2 & 51,1 & 197 & 24.6 & 579 & 12.5 & 51 & 12.4 & 127 & 56 & 45 & 647 \\
\hline 1983 & 28.8 & 475 & 237 & 249 & 53.5 & 167 & 48 & 113 & 1133 & 5.4 & 14.3 & 577 \\
\hline 1984 & 292 & 45.2 & 255 & 234 & 534 & 178 & 54 & 1199 & 105 & 6.1 & 149 & 565 \\
\hline
\end{tabular}

percent. Third, during 1981, the growth rates of M1 and $\mathrm{MQ}$ diverge dramatically, reflecting the nationwide introduction of NOW accounts. From I/1982-IV 1984, the two growth rates exhibit somewhat similar movement, although the growth rate of M1 typically exceeds that of MQ by approximately 1.5 to 2 percentage points.

An interesting feature of the growth rates is that each can be expressed as a weighted average of the growth rates of its components. Since weighting is the innovative notion behind these alternative aggregates, an investigation of these weighting schemes is an instructive way to compare MSI4 and MQ with M1. For $\mathrm{M1}$, the weights are simply each component's share of M1. The weights for the MSI are each component's share of the total expenditure for monetary services. The price of the monetary services of each asset is the difference between the yield on a risk-free store of wealth and that asset's own yield. The expenditure on each component's monetary services is this interest differential times each component's quantity. Therefore, each weight is the ratio of the expenditure on each component's monetary service to the total expenditure on monetary services.

For MQ, the weights are each component's total turnover as a percentage of nominal GNP. In other words, each component's weight is its quantity times its final product tumover rate i.e., its quantity weighted velocityl as a share of the sum of these quantity-weighted velocities over the assets in the aggregate, that is, nominal GNP.

Annual averages of these weights for the period 1970-84 are presented in table 1. The weights for the assets in M1 are aggregated into three basic groups: those for (a) currency plus travelers checks (CTC), (b) demand deposits (DD), and (c) other checkable deposits IOCD1). The first three columns of weights for MQ are for the same asset groups as for M1. The fourth column (OCD2) contains the weights for the assets in MQ that are not in M1 - money market mutual fund shares, money market deposit accounts and telephone transfer savings accounts. The weights for MSI4 are organized similarly. The first three columns contain the weights for the same asset groups as are in M1; the fourth column (OCD2) contains the weights for the assets in MQ but not in M1. The fifth column (Other) includes the weights of all the other assets in MSI4.

When comparing the weighting schemes, one notices few similarities. Both the levels, as well as the patterns of movements and the relative magnitudes, are considerably different. Only two similarities emerge: The first is the general decline of the weights of demand deposits for both M1 and MSI4. Alternatively, the weight for demand deposits in MO increases until 1980, then declines. Even after this decline, the weight for demand deposits in MQ currently 
is about the same as it was at the beginning of the 1970s, while those in M1 and MSI4 are approximately 40 percent and 55 percent lower, respectively. Second, the weights of other checkable deposits in all three aggregates, while near zero during most of the $1970 \mathrm{~s}$, have risen dramatically in the $1980 \mathrm{~s}$. This rise comesponds to the increased avalability of new checkable deposits with financial deregulation in the 1980s. The levels and relative magnitudes of these weights, however, differ substantially across aggregates. In particular, OCD1's weight in M1 is significantly larger than that in either MQ or MSI4. Moreover, OCDI's current weight is about 56 percent of demand deposits' weight in M1 and 58 percent in MSI4, while only about a third of demand deposits' weight in $\mathrm{MQ}$.

The behavior of currency's weight across all three aggregates also has been dissimilar. Currency's weight in $\mathrm{M} 1$ has risen rather consistently since 1970 , while doing just the opposite in MQ. Consequently, changes in the growth rate of currency now have a larger impact on the growth of M1 and a much smaller impact on the growth of $\mathrm{MO}$ than earlier. In contrast, currency's weight in MSI4 has not changed appreciably. The decline in demand deposits' weight, however, has led to a situation in which currency growth has a larger impact on MSI4 than does an equivalent change in demand deposit growth, a characteristic not shared by either $\mathrm{M1}$ or $\mathrm{MQ}$.

By construction, MSI4 contains a large group of assets that, while liquid, cannot be exchanged directly for goods and services. It is interesting to note how large the weights of these non-medium-of-exchange assets are in MSI4. In fact, until the last two years, the weights of non-medium-of-exchange assets in MSI4 (those classified as "other" in table 1 / have been $1-1 / 2$ to 2 times larger than the weights of the medium-ofexchange assets the sum of the first four MSI4 weightsl. Onlv in 1983 and 1984 have the weights of medium-of-exchange and non-medium-of-exchange assets approached equality. Consequently, until recently, a one percentage-point change in the rate of growth of assets that cannot be exchanged directly for goods and services had a substantially larger impact on the growth of MSI4 than did a one percentagepoint change in the rate of growth of transaction balances.

\section{MOCH W

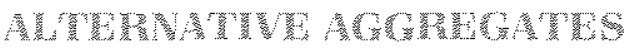

For an aggregate to be useful as a short-run intermediate target of monetary policy, it must have a stable, predictable relationship with the goals of policy. Since the growth of nominal income is one of the principal goals of monetary policy, it is important that an aggregate's income velocity be predictable if it is to be used for short-run economic stabilization.

We begin with a simple comparison of the levels of the velocities of $\mathrm{M1}, \mathrm{MSl} 4$ and MQ. These velocities, normalized to $\mathrm{V} 1970=1.0$, are presented in chart $2 . "$ The velocities of $\mathrm{M} 1$ and $\mathrm{MQ}$ follow similar pattens. Both appear to increase at a faily constant rate until 1980, then acceleate through 1981 and dechne markedly after the nationwide introduction of NOW accounts. Moreove: both have increased since mid1983. The major difference is that the velocity of $\mathrm{M} 1$ was larger than that of MO until IV/1980 and has been below it since the introduction of NOWs." While MSI4 velocity has exhibited generally similar movements since the end of 1980 , it grew much more slowly than either $\mathrm{M} 1$ or $\mathrm{MQ}$ velocity up to the beginning of 1978 and then considerably more rapidly from 1978 to the end of $1980^{18}$ Moreover, as one would expect given the composition of MSI4, its velocity is significantly lower than that of the other two aggregates, reflecting the slower turnover rate of the non-medium-of-exchange assets that are included in it.

The quarter-to-quarter growth rates of the velocities are presented in chart 3 . These data indicate that the growth rates of M1 and MO differ little over the period. Indeed, the most significant difference in the growth rates of $\mathrm{Ml}$ and MQ occurred in the first two quarters of 1981 . The velocities of both aggregates grew rapidly during the first quarter of 1981, but the growth in the velocity of $\mathrm{MO}(33.1$ percent was nearly double that of M1 18.2 percent. Furthermore, the velocity of M1. declined in the second quarter of 1981, while that of MQ increased at a rate of about 1 percent. In all other cases, the turning points in growth lates of $M 1$ and $\mathrm{MQ}$ velocities coincide. In contrast, the growth rate of MSI4 velocity differ's from the others, being substan-

\footnotetext{
18The velociles for MQ and MSI4 are index numbers and, as such, have ro dimension. Hence, they must be normalized to some arbitrarily chosen base period ( $/ 970$ in this case). M1 velocity is normalized similarly to facilitate the comparisons.

"This is consistent with the eatler observation that simple-sum M1 growth has been rapid relative to that of $\mathrm{MQ}$ since the nationwide introduction of NOWs.

1aFrom /1/1970 to IV/1977. MS14 velocity grew at a 0.3 percent annual rate while $M Q$ and $M 1$ velocities grew at 2.9 percent and 3.2 percent rates, respectively. MSI4 velocity growth accelerated to a $6.5 \mathrm{per}-$ cent rate from $1 / 1978$ to $\mathrm{W} / 1980$ while the growth of $\mathrm{MO}$ and $\mathrm{M} 1$ velocities rose only to 3.7 percent and 3.2 percent tates, respectively.
} 
Chart 2

Velocities of Monetary Aggregates

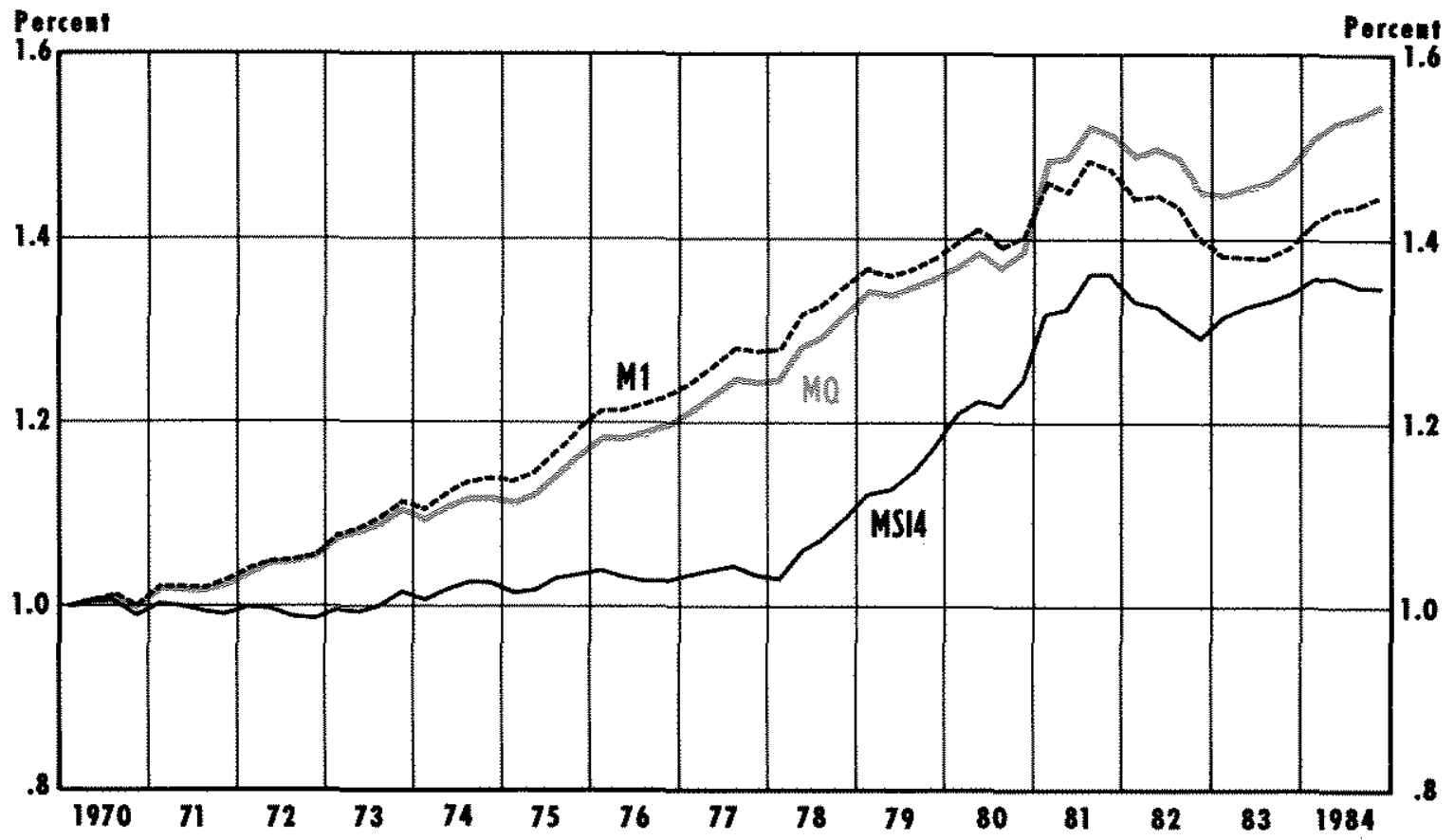

Chant 3

Growth Rate of Velocities of Monetary Aggregates

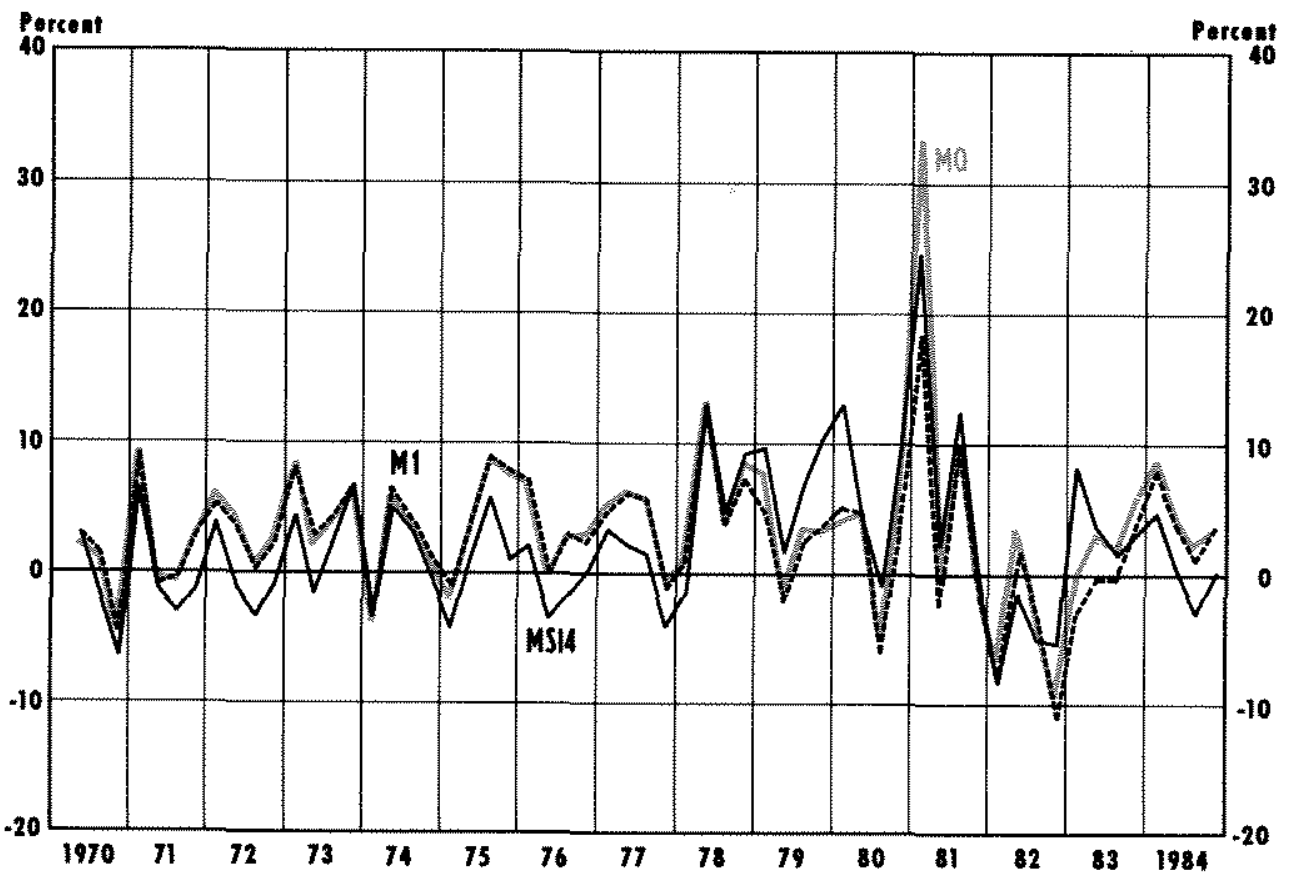




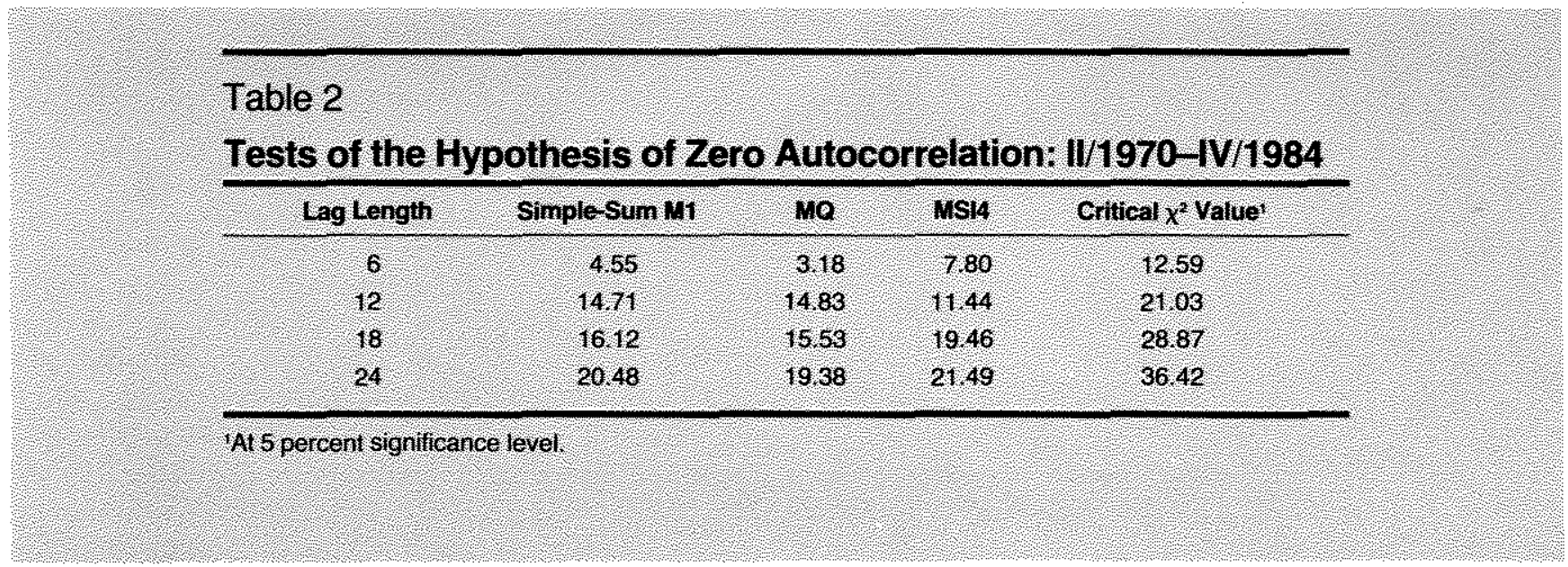

lially below them until late 1978 and above the others until late 1980 . Since 1980 the growth rates of the velocity of all these aggregates have behaved similarly.

\section{There}

Studies have shown that econometric forecasts of M1 velocity growth tend to produce relatively large forecast errors. This result may be due in part to the fact that velocity growth tends to fluctuate randomly around a fxed mean, so that the expected future growth rate in $M 1$ velocity is unrelated to its past growth rates. That is to say that $\mathrm{M} 1$ velocity possesses no regularities that will enable it to be predicted on the basis of its own past history. If a series contains such regularities, then its past history provides some basis to predict its future, especially for a short time into the future."?

If the growth rates of $\mathrm{MQ}$ and MSI4 velocities also contain no such regularities, then they will be just as difficult to predict as M1 velocity from their own past histories, and may be just as difficult to predict from an econometric model as well. Consequently, it can be argued that a sufficient condition for MQ and MSI4 to be preferable to $\mathrm{M} 1$ as intermediate policy targets is that the growth rates of their velocities exhibit regular ities not exhibited by M1 velocity. of course, this finding would not preclude the possibility that these velocities could not be predicted on the basis of information not contained in the past history of the series itself. Nevertheless, if no such regularities are present,

\footnotetext{
${ }^{9}$ Granger (1980) has shown that a series is essentially randoma if it has no predictable pattern to it. Thus, a time series, $X_{i}$ is random if the correlation between $X_{1}$ and $X_{1-1}$ is not significantly different from zero for all $\mathrm{s}$.

20 For example, see Hein and Veugeters (1983) and Nelson and Plosser (1982).
}

it would tend to suggest that it may be no easier tc predict MSI4 and MQ velocities than it is for M1 velocity.

To test whether the growth of MSI4, MQ or M1 velocity contains such regularities, correlation coef. ficients between past and current values of velocity growth are calculated over the period II/1970 to IV/1984. If these comrelations are not statistically significant, then past values of velocity growth do not contain information helpful in predicting current velocity growth and, hence, velocity growth cannot be predicted by its own past history. The chi-squared statistics for testing whether the correlations between past and current rates of velocity growth are different from zero for lag lengths of $6,12,18$ and 24 quarters are presented in table 2 . None of these statistics is statistically significant at the 5 percent level. Hence, the hypothesis that each of these series cannot be predicted by its own past cannot be rejected. In other words, the quarterly growth of the weighted aggregates'velocities is no more easily predicted by their own past than is the quarterly growth of M1 velocity."

Since the above test indicates that the velocity growth of each of these monetary aggregates varies randomly around its mean, it would be instructive to examine whether the velocity growth of any one aggregate varies significantly less than that of the others. The means and standard deviations of the growth rates given in table 3 indicate that the standard deviation of the growth rates of velocity around their mean levels is not significantly different for any of the aggregates." Indeed, the standard deviation of the growth

\footnotetext{
${ }^{2}$ This result is generally consistent with Spindt's (1985).

22None of the tests of the hypothesis that the variances are equal could be rejected at the 5 percent level.
} 


\section{Table 3}

Means and Standard Deviations of the Growth Rates of Various Velocity Measures: II/1970-N/T984

\begin{tabular}{|c|c|c|}
\hline Aggregate & Nean & $\begin{array}{l}\text { Standard } \\
\text { Deviation }\end{array}$ \\
\hline Simple Sum MI & 2.67 & 499 \\
\hline $\mathrm{MO}$ ४४४ ४४ ४ & 317 & 585 \\
\hline $\mathrm{MSI} 4$ & 221 & 576 \\
\hline
\end{tabular}

rates is smallest for M1. Thus, the evidence suggests that the growth rates of the velocities of MSI4 and MO do not appear to be more easily predicted nor any less variable than the growth rate of M1 velocity. Hence, these aggregates may not be better intermediate monetary targets than M1.

While the above analysis indicates that MQ and MSI4 have not been preferable intermediate targets over M1 during the II/1970 to IV/1984 period, it does not preclude that either (or both) of these aggregates may be better targets during the period of financial innovation, $\mathrm{V} / 1981-\mathrm{V} / 1984$. The evidence already presented, however, implies that this is not the case. In particular, as seen in charts 2 and 3 , both the level and the growth rate of each velocity behaved similarly from I/1981 to IV/1984. All three velocities fell in mid-1981 and have rebounded since early 1983. Furthemore, even though the growth of each velocity is more variable during this period than it was during the preceding one, the standard deviations across velocity growth rates are not statistically different. Like the results for the entire period, the growth of M1 velocity is the least variable over the I/1981-IV/1984 period. Consequently, there have not been any substantive changes in the relative performances of these three aggregates during the past four years."

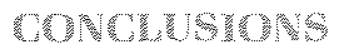

The introduction of new financial instruments and the recent financial deregulation have confused further the distinction between money and near-money. One response to this confusion has been the construc-

${ }^{23}$ This is generally consistent with the results in Batten and Thomton (1985) who found that MQ and MS14 did not outperform M1 in a St. Louis-type equation during the $\mathrm{I} / 1981$ to $\mathrm{l} / / 1984$ period. tion of two monetary aggregates as alternatives to the simple-sum measures currently reported by the federal Reserve. These alternatives are the monetary services indexes and MQ. Each of these new aggregates is a weighted index of the same financial assets that constitute the various measures of money as currently defined. The difference between the monetary services indexes and MQ lies primarily in the weighting scheme employed to measure the monetary services provided by the assets that compose each aggregate. The monetary services indexes use opportunity costs of holding these financial assets to calculate the weights, while MO employs the turnover rates of these assets. When investigated, these weighting schemes differed substantially across the three monetary aggregates examined.

From a policymaking viewpoint, the primary motivation for examining different monetary aggregates is to find the one most closely associated with nominal GNP. In this paper, we compared the growth and the stability of the velocity of these alternative weighted monetary aggregates with the conventional simplesum M1. We found that the growth rate of M1 velocity was somewhat slower than that of MO since the nationwide introduction of NOW accounts in 1981; however, there was little difference in the movements of these growth rates. Furthermore, the $\mathrm{MQ}$ velocity growth was neither less variable nor more predictable than that of M1.

With respect to the broadest monetary services index (MSI4), we found some significant differences in its growth rate and velocity relative to $\mathrm{M} 1$ and $\mathrm{MQ}$; however, there was no difference in the predictability or the variability of MS14 velocity growth. Consequently, neither MSI4 nor MQ has demonstrated any apparent gain over M1 for policy purposes, and both are more difficult to calculate.

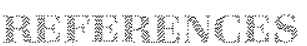

Barnett, Wiliam A. "Economic Monetary Aggregation: An Application of Index Number and Aggregation Theory," Journal of Econometrics (September 1980), pp. 11-48.

Barnett, Willam A., and Paul A. Spindt. Divisia Monetary Aggregates, Staff Study No. 116 (Board of Governors of the Federal Reserve System, May 1982).

Barnett, William A., Edward K. Offenbacher and Paul A. Spindt. "The New Divisia Monetary Aggregates," Joumal of Political Economy (December 1984), pp. 1049-85.

Batten, Dallas S., and Daniel L. Thornton. "Weighted Monetary Aggregates As Intermediate Targets," Federal Reserve Bank of St. Louis Research Paper No. 85-010 (1985). 
- "M1 or M2: Which Is the Better Monetary Target?" this Review (June/July 1983), pp. 36-42.

Brown, W. W., and G. J. Santoni. "Monetary Growth and the Timing of Interest Rate Movements," this Review (AugustSeptember 1983), pp, 16-25

Chetty, V.K. "On Measuring the Nearness of Near-Moneys," American Economic Review (June 1969), pp. 270-81.

Farr, Helen T., and Deborah Johnson. "Revisions in the Monetary Services (Divisia) Indexes of Monetary Aggregates," Mimeo, Board of Governors of the Federal Reserve System (1985).

Fisher, Irving. The Purchasing Power of Money (New and rev. ed., A. M. Kelley, 1963) pany, 1922).

The Making of Index Numbers (Houghton-Mifflin Com-

Friedman, Milton. "The Quantity Theory of Money - A Restatement," in Stcidies in the Quantity Theory of Money (The University of Chicago Press, 1956), pp. 3-21.

Friedman, Milton, and David Meiselman. "The Relative Stability of Monetary Velocity and the Investment Multiplier in the United States, 1897-1958," in Stabilization Policies (PrenticemHall, 1963), pp. $165-268$

Friedman, Miton, and Anna Jacobson Schwartz. Monetary Statis* tics of the United States (National Bureau of Economic Research, 1970 ).

Granger, C. W. J. Forecasting in Business Economics (Academic Press, 1980).

Hafer, R. W. "Money, Debt and Economic Activity, this Review (June/July 1984), pp. 18-25.

"The FOMC in 1983-84: Setting Poticy in an Uncertain World," this Review (Aprit 1985), pp. 15-37.

Hamburger, Michael J. "The Demand for Money by Households, Money Substitutes, and Monetary Policy, "Joumal of Political Economy (December 1966), pp. 600-23.
Hein, Scott $E_{1}$, and Paul T. W. M. Veugelers. "Predicting Velocity Growth: A Time Series Perspective " this Review (October 1983), pp. $34-43$.

Keynes, John Maynard. The General Theory of Employment, interes and Money (Marcourt, Brace and Company, 1936).

Laidler, David. "The Deffnition of Money," Joumal of Money, Credin and Banking (August 1969), pp. 508-25.

Marshall, Alfred. Money, Credit and Commerce (London: MacMillan and Company, 1923).

Mason, Will E. "The Empirical Definition of Money: A Critique," Economic Inquiry (December 1976), pp. 525-38.

Melvin, Michael. "The Vanishing Liquidity Effect of Money on Interest: Analysis and Implications for Policy," Economic Inquiry (Apri 1983), pp. 188-202.

Nelson, Charles R., and Charles 1. Plosser, "Trends and Random Walks in Macroeconomic Time Series: Some Evidence and Implications," Joumal of Monetary Economics (September 1982), pp. $139-62$.

Pesek, Boris P., and Thomas R. Saving. Money, Wealth, and Economic Theory (The MacMilan Company, 1967).

Pigou, A. C. "The Value of Money," Quarterly Joumal of Economics (November 19+7), pp. 38-65.

Spindt, Paul A. "Money is What Money Does: Monetary Aggregation and the Equation of Exchange," Journal of Political Economy (February 1985), pp. 175-204.

"Money is What Money Does: A Revealed Production Approach to Monetary Aggregation," Special Studies Paper No. 177 (Board of Governors of the Federal Resene System, June 1983).

Thornton, Daniel L. "The FOMC in 1981: Monetary Control in a Changing Financial Environment," this Review (April 1982), pp. $3-$ 22.

1983), pp. 5-13 